\title{
Properties and Biodegradability of Thermoplastic Starch Obtained from Granular Starches Grafted with Polycaprolactone
}

\author{
Z. B. Cuevas-Carballo, S. Duarte-Aranda, and G. Canché-Escamilla \\ Centro de Investigación Científica de Yucatán, A.C., Calle 43, No. 130, Col. Chuburná de Hidalgo, 97205 Mérida, YUC, Mexico \\ Correspondence should be addressed to G. Canché-Escamilla; gcanche@cicy.mx
}

Received 28 April 2017; Accepted 25 May 2017; Published 6 July 2017

Academic Editor: Marta Fernández-García

Copyright ( 2017 Z. B. Cuevas-Carballo et al. This is an open access article distributed under the Creative Commons Attribution License, which permits unrestricted use, distribution, and reproduction in any medium, provided the original work is properly cited.

Granular starches grafted with polycaprolactone (St-g-PCL) were obtained using N-methylimidazole (NMI) as a catalyst. The effect of the starch/monomer ratio and catalyst content was studied to obtain different levels of grafted PCL. The highest grafting percentage (76\%) and addition (43\%) were achieved for reactions with a starch/monomer ratio of $50 / 50$ and $25 \%$ catalyst. The grafting of PCL on the starch granule was verified by the emergence of the carbonyl group in the FTIR spectra and the increased diameter of the grafted starch granule. Thermoplastic starch from ungrafted starch (TPS) and grafted starch (TPGS) was obtained by mixing ungrafted or grafted starch granules with water, glycerol, or sorbitol in a mixer. TPS and TPGS behave as plastic materials, and their mechanical properties depend on the type of plasticizer used. Materials with glycerol as the plasticizer exhibited less rigidity. The presence of starch-g-PCL results in a dramatic increase in the elongation of the thermoplastic material. The starch present in the TPS or TPGS was completely biodegraded while the grafted PCL was partially biodegraded after the enzymatic degradation of the materials.

\section{Introduction}

Biodegradable polymers represent a solution to the problems of contamination caused by conventional synthetic polymers [1-5]. Starch is a completely biodegradable polysaccharide synthesized by a large number of plants and is inexpensive $[2$, 6-9]. Its use in the production of biodegradable materials can simultaneously reduce the dependence on petroleum and the problem of plastic waste $[4,10-12]$. However, there are limited ways of using starch in its granular form to obtain thermoplastic materials by conventional processing techniques such as extrusion or injection [13-17]. Poor mechanical properties are obtained due to the thermal decomposition of granular starch before melting occurs, to the high water absorption and poor interaction with other materials $[6,11,13,18]$. To overcome the shortcomings of thermoplastic-based starch, the starch has been plasticized $[7,12,15,17]$ or modified by grafting nondegradable monomers, such as styrene [19] and methyl methacrylate $[8,20]$ to the backbone $[21]$, as a way of obtaining a material that can be processed by extrusion or injection. However, in the last case, the grafted starches obtained are partially biodegradable [22].

Other methods used for the chemical modification of starch have included grafting of chains of biodegradable polyesters, such as polycaprolactone (PCL) $[2,23]$ and poly(L-lactide) (PLLA) [13], by reactions of their hydroxyl groups or through ring-opening graft polymerization of monomers with starch as the initiation site of polymerization. In these studies, graft efficiency close to the $60 \%$ was obtained, the mechanical properties were improved, and a completely biodegradable copolymer was obtained. The starch-g-polyester copolymers have been used as compatibilizers in blends of starch with other polymers [13].

There is limited information on the use of granules starches grafted with biodegradable polyesters to obtain thermoplastic grafted starches (TPGS) by using plasticizers, although the granule starch has been modified, either physically or chemically, in various ways and graft copolymerization has been extensively studied, which opens up new research possibilities. 
TABLE 1: Formulations used in grafting reactions of polycaprolactone on starch granules.

\begin{tabular}{|c|c|c|c|c|c|c|c|}
\hline Materials & St-g-PCL1 & St-g-PCL2 & St-g-PCL3 & St-g-PCL4 & St-g-PCL5 & St-g-PCL6 & St-g-PCL7 \\
\hline Starch $[\mathrm{g}]$ & 5 & 5 & 5 & 5 & 5 & 100 & 100 \\
\hline$\varepsilon$-Caprolactone $(\varepsilon$-CL) $[\mathrm{g}]$ & 5 & 5 & 5 & 2.5 & 7.5 & 100 & 50 \\
\hline N-Methylimidazole (NMI) [g] & 0.625 & 1.25 & 1.875 & 1.25 & 1.25 & 25 & 25 \\
\hline
\end{tabular}

This paper investigates thermoplastic grafted starches (TPGS) and considers two processes used to obtain them. The first one is the reaction process for obtaining granular grafted starch with biodegradable polyester (polycaprolactone, PCL) and the second process involves obtaining thermoplastic starches (TPGS) from grafted starch. In the first process, the ratio between the starch and the monomer was studied, and the influence of the amount of catalyst used on the grafting parameters was investigated. In the second process, the influence of both the ratio between the amount of grafted starch and plasticizer used and the type of plasticizer on the properties and enzymatic degradation of the TPGS was studied.

\section{Materials and Methods}

2.1. Grafting Copolymerization. Corn starch was purchased from Unilever Manufacturera, S. de R.L. de C.V. $\varepsilon$ caprolactone monomer $(\varepsilon-\mathrm{CL})$ with $97 \%$ purity and catalyst $\mathrm{N}$-methylimidazole (NMI) were of reagent grade and were purchased from Sigma-Aldrich Química, S. de R.L. de C.V. Starch particles were grafted according to a method reported in the literature [23]. The procedure was as follows: starch (dry basis), $\varepsilon$-CL monomer, and catalyst NMI were placed into a glass reactor equipped with a mechanical stirrer and a condenser. The reactor was placed in a glycerin bath at $150^{\circ} \mathrm{C}$ and the mixture was stirred for a certain amount of time. The polymerization yield was determined gravimetrically. In Table 1, the formulations used for obtaining polycaprolactone-grafted starch are shown.

2.2. Determination of Grafting Parameters. Extraction with toluene was conducted to dissolve remains of the $\varepsilon$ CL monomer, catalyst, and ungrafted polymer chains (homopolymer). After toluene extraction, the material was dried under vacuum to a constant weight. Grafting parameters are determined from the weights before and after the extraction $[3,24]$ using the following equations:

$$
\begin{aligned}
& \text { Graft }(\%)=\left[\frac{\text { PCL grafted weight }}{\text { Starch weight }}\right] \times 100 \\
& =\left[\frac{w_{\text {if }}-w_{\text {st }}}{w_{\text {st }}}\right] \times 100
\end{aligned}
$$

Addition (\%)

$$
\begin{aligned}
& =\left[\frac{\text { PCL grafted weight }}{\text { Total weight copolymer St-g-PCL }}\right] \times 100 \\
& =\left[\frac{w_{\text {if }}-w_{\text {st }}}{w_{\text {if }}}\right] \times 100,
\end{aligned}
$$

$$
\begin{aligned}
& \text { Grafting Efficiency (\%) } \\
& \quad=\left[\frac{\text { PCL grafted weight }}{\text { PCL formed weight }}\right] \times 100 \\
& \quad=\left[\frac{w_{\text {if }}-w_{\text {st }}}{w_{\mathrm{hp}}+\left(w_{\text {if }}-w_{\text {st }}\right)}\right] \times 100,
\end{aligned}
$$

where $w_{\text {if }}$ is the weight of the product obtained after extraction (the insoluble fraction), in grams $(\mathrm{g}) ; w_{\text {st }}$ is the weight of starch loaded in the reaction, in grams $(\mathrm{g})$; and $w_{\mathrm{hp}}$ is the weight of the homopolymer formed in the reaction, in grams (g).

2.3. Characterization of Grafted Granule Starch. The morphology of the particles was observed using a JEOL 6360LV SEM scanning electron microscope. The particles were covered with a gold surface layer to improve contrast. The size of the grafted and ungrafted starch granules was analysed with a Coulter Counter LS100Q after the granules were dispersed in deionized water. FTIR analysis of starch and grafted starch was performed in a Nicolet 870 Fourier transform infrared spectrophotometer, in a wavenumber range from 4000 to $400 \mathrm{~cm}^{-1}$, with 16 scans and a resolution of $4 \mathrm{~cm}^{-1}$. X-ray diffractograms were recorded on a Siemens D-5000 diffractometer with a $\mathrm{Cu}-\mathrm{K} \alpha$ radiation source (wavelength $\lambda=1.5418 \AA$ ). The samples were exposed to the X-ray beam with the X-ray generator running at $34 \mathrm{kV}$ and $25 \mathrm{~mA}$, and a step time of $6 \mathrm{sec}$ and step size of $0.04^{\circ}$ were used. TGA thermograms were obtained on a Perkin Elmer TGA-7 thermogravimetric balance in a temperature range from 40 to $700^{\circ} \mathrm{C}$, with a heating rate of $10^{\circ} \mathrm{C} / \mathrm{min}$ and in nitrogen atmosphere.

\subsection{Preparation and Characterization of the Thermoplastic} Starch. Thermoplastic materials with grafted (TPGS) and ungrafted (TPS) granular starch were obtained with glycerol or sorbitol added as plasticizers. The ratio of starch (or grafted starch) to water to glycerol/sorbitol was $50 / 25 / 25$ or $50 / 15 / 35$. The ungrafted or grafted granule starch was first blended with water using a mixer and stored overnight. Subsequently, it was mixed with glycerol or sorbitol and stored overnight. The mixtures were manually fed into a Brabender Plasticorder mixer for $10 \mathrm{~min}$ at $150^{\circ} \mathrm{C}$ with a rotation speed of $40 \mathrm{rpm}$. The blends were molded at $150^{\circ} \mathrm{C}$ in a Carver Laboratory press under a force of $10,000 \mathrm{lbs}$ to obtain samples for mechanical experiments.

Tensile tests for TPS and TPGS were conducted with a Shimadzu AGS-X universal machine by following the ASTM D638-14 method [25]. The analyses were performed after 
TABLE 2: Effect of reaction conditions on the grafting parameters.

\begin{tabular}{|c|c|c|c|c|c|c|}
\hline Code & Starch/monomer relation & Catalyst (g) & Monomer (g) & Graft (\%) & Addition (\%) & Grafting efficiency (\%) \\
\hline St-g-PCL1 & $50 / 50$ & $0.625(12.5 \%)$ & 5 & 13 & 11 & 28 \\
\hline St-g-PCL2 & $50 / 50$ & $1.25(25 \%)$ & 5 & 68 & 40 & 88 \\
\hline St-g-PCL3 & $50 / 50$ & $1.875(37.5 \%)$ & 5 & 64 & 39 & 72 \\
\hline St-g-PCL4 & $75 / 25$ & $1.25(25 \%)$ & 2.5 & 42 & 30 & 92 \\
\hline St-g-PCL5 & $25 / 75$ & $1.25(25 \%)$ & 7.5 & 21 & 18 & 22 \\
\hline St-g-PCL6 & $50 / 50$ & $25(25 \%)$ & 100 & 76 & 43 & 72 \\
\hline St-g-PCL7 & $75 / 25$ & $25(25 \%)$ & 50 & 35 & 26 & 50 \\
\hline
\end{tabular}

equilibrating the samples, according to the ASTM D618-13 standard [26], for 2 days at temperatures of $23 \pm 2^{\circ} \mathrm{C}$ and at relative humidities of $50 \pm 5 \%$ and at a crosshead speed of $5 \mathrm{~mm} / \mathrm{min}$. The specimens (type IV) were cut from the $1 \mathrm{~mm}$ hot-pressed molded sheets using a die cutting machine. The JEOL 6360LV examines the failure surface of the thermoplastic starch after mechanical tests; the samples were coated with gold film before examination to improve the contrast. The storage moduli and $\tan \delta$ curves of samples were obtained on a Perkin Elmer DMA-7 mechanical dynamic analyser with a parallel plate/disc mode at $1 \mathrm{~Hz}$, at a heating rate of $5^{\circ} \mathrm{C} / \mathrm{min}$, and at a temperature range of -100 to $50^{\circ} \mathrm{C}$. The samples (10 $\mathrm{mm}$ in diameter) were cut from the $1 \mathrm{~mm}$ hot-pressed molded sheets. Thermogravimetric analysis of TPS and TPGS was performed with a Perkin Elmer TG-7 thermogravimetric balance at a heating rate of $10^{\circ} \mathrm{C} / \mathrm{min}$ and a temperature range of 40 to $700^{\circ} \mathrm{C}$ under nitrogen atmosphere. XRD measurements were performed in a Siemens D-5000 diffractometer with a $\mathrm{Cu}-\mathrm{K} \alpha$ radiation source (wavelength $\lambda=$ $1.5418 \AA$ ) and a step time of $6 \mathrm{sec}$ and a step size of $0.04^{\circ}$.

2.5. Enzymatic Degradation. The enzymatic degradation was performed according to the methods reported in the literature [11, 22] using $\alpha$-amylase from Bacillus licheniformis and glucoamylase from Aspergillus niger, both purchased from Sigma-Aldrich. Incubations were carried out at $37^{\circ} \mathrm{C}$ in $2.5 \mathrm{~mL} 0.1 \mathrm{M}$ acetate buffer ( $\mathrm{pH} \mathrm{5.0)}$ containing $50 \mu \mathrm{L}$ of Merthiolate to prevent microbial growth. The concentration of the enzymes was $7.5 \mathrm{U} / \mathrm{mL}$ of $\alpha$-amylase and $15 \mathrm{U} / \mathrm{mL}$ of glucoamylase. The samples were of size $1 \mathrm{~mm} \times 7.5 \mathrm{~mm} \times$ $7.5 \mathrm{~mm}$. After a certain time, the samples were filtered and the solids were washed with distilled water and then dried to constant weight. The solids obtained after enzymatic hydrolysis were observed using a JEOL 6360LV SEM scanning electron microscope and characterized by FTIR and thermogravimetric analysis using the same conditions as in the characterization of the thermoplastic starches.

\section{Results and Discussion}

3.1. Characterization of Grafted Granule Starch. Table 2 shows the grafting parameters obtained after the extraction with toluene. Grafting reactions with different amounts of catalyst were carried out while maintaining a constant amount of starch and monomer. It is observed that an increase in the amount of catalyst $(12.5 \%$ to $25 \%)$ tends to increase the grafting parameters. However, similar graft values were obtained for reactions with higher amounts of catalyst, 25 and 37.5\% (St-g-PCL2 and St-g-PCL3), which can be attributed to the lower diffusion of the caprolactone in the reaction medium. As the concentration of catalyst increases, there is a higher reaction rate and a higher viscosity of the reaction medium [23]. The lower grafting efficiency obtained with $37.5 \%$ of catalyst in comparison with $25 \%$ of catalyst confirms this assumption. To obtain different levels of grafted polycaprolactone in subsequent materials, reactions were performed by varying the percentage of the monomer while keeping both the amount of catalyst (25\% by weight) and the amount of starch constant. Higher grafting parameter values were observed for a low amount of monomer compared with a high amount of monomer (St-g-PCL4 and St-gPCL5), which is attributed to the homopolymerization being the principal reaction at high levels of caprolactone. To obtain enough material for making thermoplastic starches, the reactions were scaled (St-g-PCL6 and St-g-PCL7), and they showed similar grafting parameters to their counterparts (St-g-PCL2 and St-g-PCL4).

Figure 1 shows SEM micrographs of the grafted starch granules. It can be observed that the granular starches maintained their integrity and their surfaces were modified by the grafted aliphatic polyester chains. Starch particles are covered with a layer of polycaprolactone and a marked increase in the average size was observed. The increase of the granular size was confirmed in Figure 1(d), where the size distribution curves for the starch and grafted starch are shown. Average sizes of $14 \mu \mathrm{m}$ and $25 \mu \mathrm{m}$ were obtained for the ungrafted and grafted starch, respectively. These results are similar to those reported in the literature [20,21].

The grafting of polycaprolactone onto starch granules was confirmed by FTIR and XRD spectra. Figure 2(a) displays infrared (IR) spectra of the starch, PCL, and grafted starch with polycaprolactone. The IR spectrum of the starch shows a broad band between 3700 and $3000 \mathrm{~cm}^{-1}$ which is attributed to the stretching of the hydroxyl group $(-\mathrm{OH})$ present in the anhydroglucose unit; also a peak at $1645 \mathrm{~cm}^{-1}$ due to the bending of the same group is observed [27]. In addition, the spectrum exhibits two signals at $2930 \mathrm{~cm}^{-1}$ and $2890 \mathrm{~cm}^{-1}$, which correspond to the asymmetric and symmetric stretching of methylene group $\left(-\mathrm{CH}_{2}\right)$, respectively [28]. The PCL spectrum has an intense peak at $1730 \mathrm{~cm}^{-1}$, which corresponds to the stretching of the carbonyl group $(\mathrm{C}=\mathrm{O})$ 


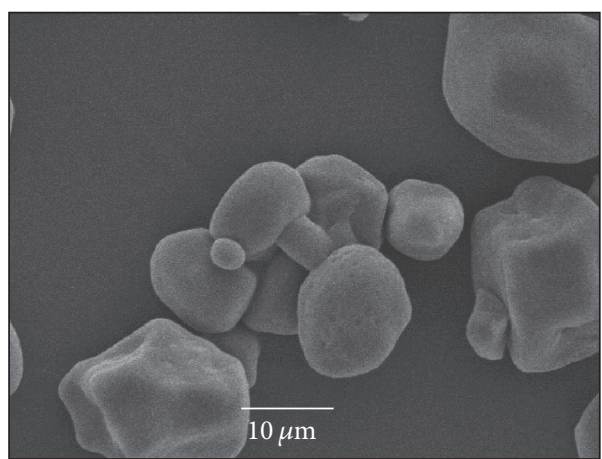

(a)

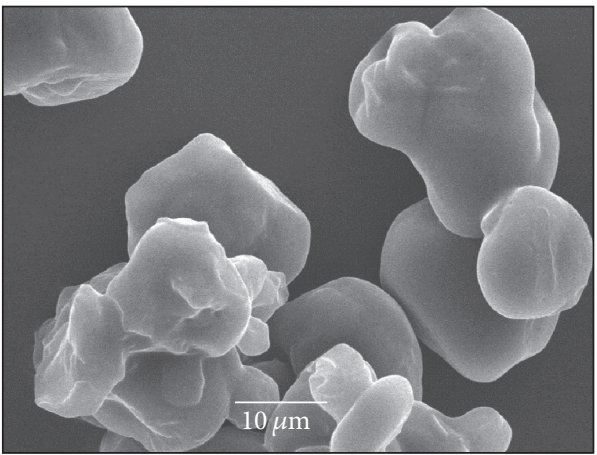

(c)

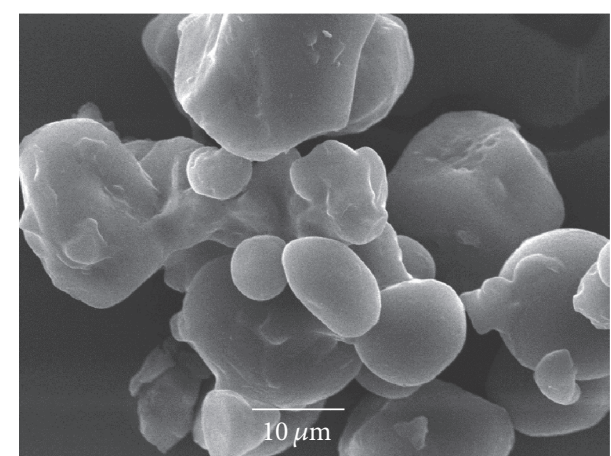

(b)

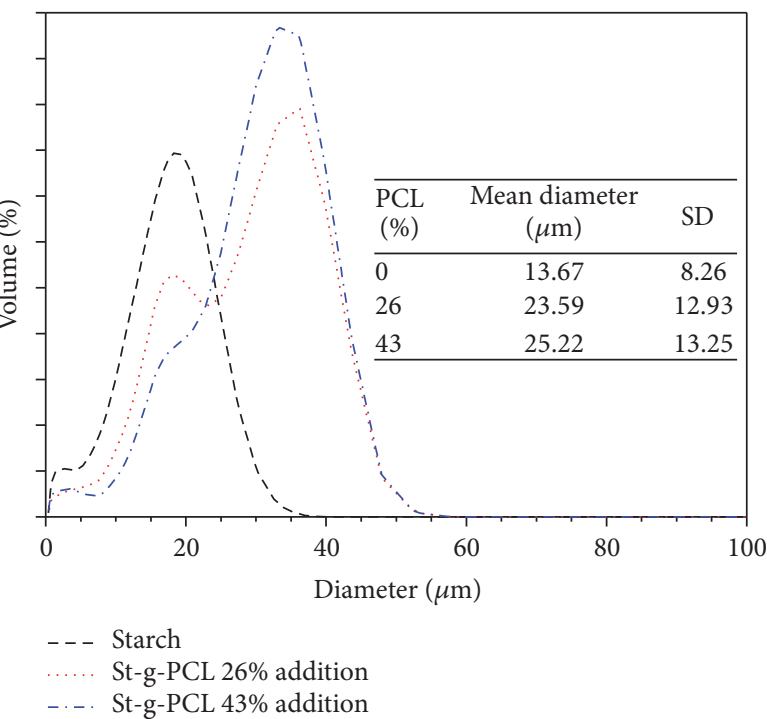

(d)

FIGURE 1: SEM micrographs of (a) granular starch, (b) granular starch with $30 \%$ of PCL, (c) granular starch with $40 \%$ of PCL, and (d) the particle size distributions for grafted and ungrafted granule starch.

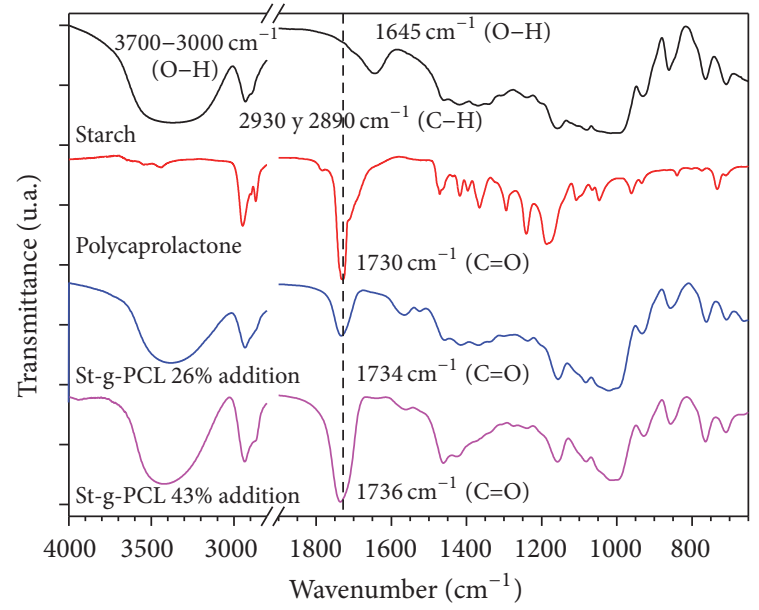

(a)

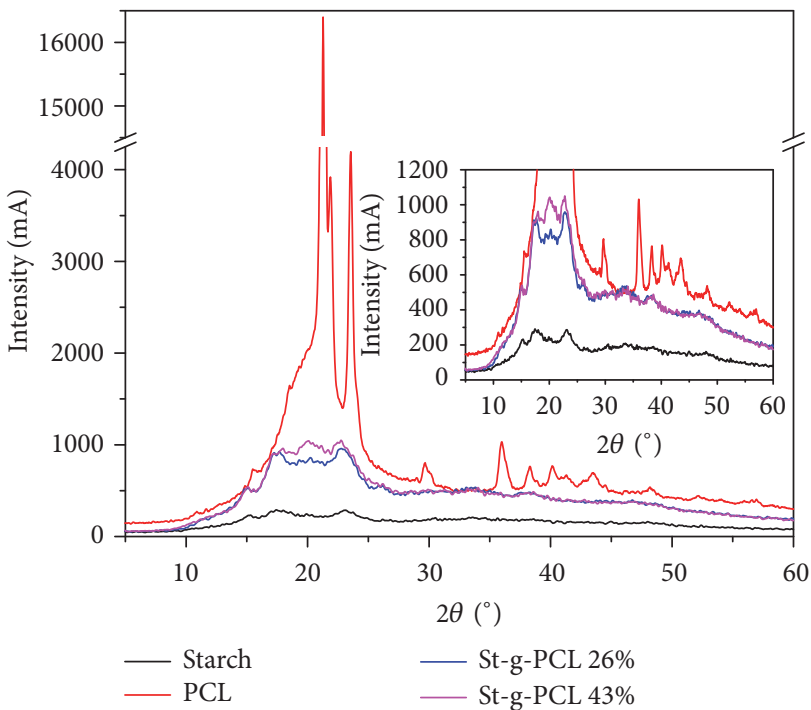

(b)

FIGURE 2: FTIR spectra (a) and XRD diffractograms (b) of starch, PCL, and grafted starch with PCL. 


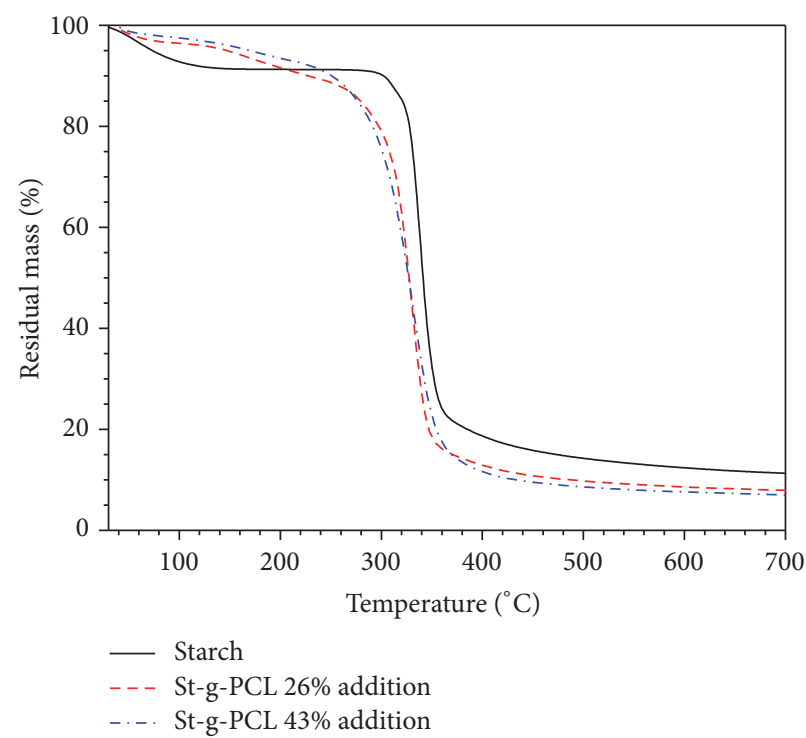

(a)

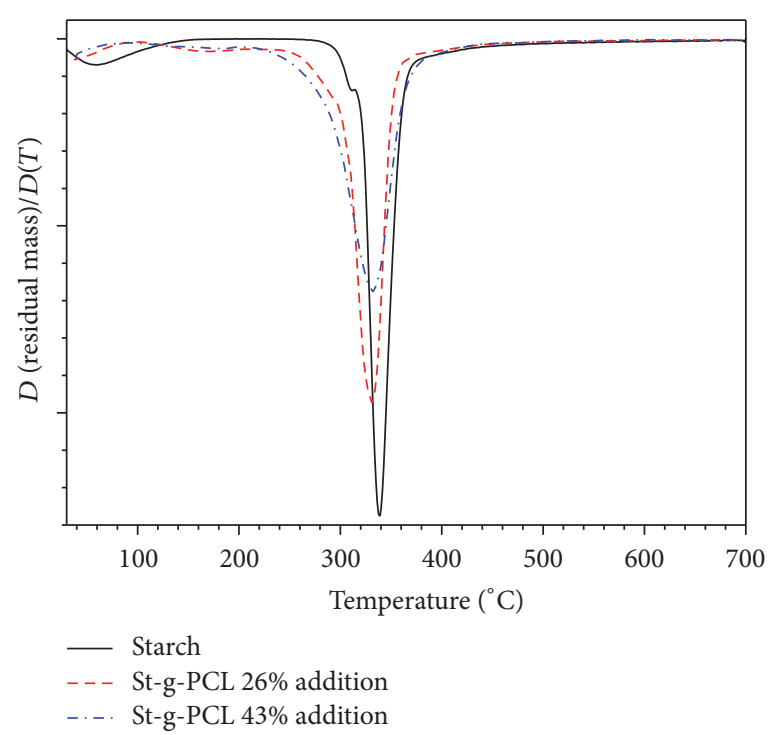

(b)

FIGURE 3: TGA (a) and DTGA (b) thermograms of starch and grafted starch with different content of PCL.

of the polyester [3, 23]; moreover, characteristic stretching signals from the $-\mathrm{CH}_{2}$ group can be observed at $2950 \mathrm{~cm}^{-1}$ and $2900 \mathrm{~cm}^{-1}$. The spectra for the grafted starch show the starch signals and the appearance of the signal due to the carbonyl group of polycaprolactone (PCL), which confirms the grafting of polymer on the starch chains. Additionally, the signal intensifies with increasing addition of PCL and exhibits a slight displacement towards higher values. It has been reported that the ester groups $(\mathrm{C}=\mathrm{O})$ absorb energy at $1740-1715 \mathrm{~cm}^{-1}$ when they are associated with carbon-carbon double bonds $(\mathrm{C}=\mathrm{C})$ or aromatic hydrocarbons [28-31].

Figure 2(b) shows the XRD diffractograms of the starch, the PCL, and the grafted starch with PCL. It can be observed in the starch diffractogram peaks at $2 \theta=15.3,17.4$, and $23.1^{\circ}$ which are typical for corn starch $[32,33]$. The PCL diffractogram shows two main diffraction peaks at $2 \theta=21.3$ and $23.6^{\circ}$ [34]. In grafted starch, an increase in the intensity of the diffraction patterns occurs, which is ascribed to a higher crystalline structure. In addition to the peaks associated with starch, new signals appear at 20.2 and $22.8^{\circ}$, attributed to the PCL grafted on the starch surface; moreover, an increase in the peaks height is observed with a greater amount of grafted polymer. It has been reported that low crystallinity may be promoted by the decrease of the hydrogen bonds during the grafting process due to the formation of esters and that the grafted polymer chains are too short to form crystals [23].

In the TGA (Figure 3(a)) and DTGA (Figure 3(b)) thermograms, a decrease in the initial weight loss for grafted starch was observed, which indicated a lower hydrophilic character due to the presence of the PCL. Two decomposition zones are observed in the range of $180-350^{\circ} \mathrm{C}$; the first is attributed to PCL degradation and the second proves that both polymers are thermally decomposed in the range of $250-350^{\circ} \mathrm{C}$ with a maximum decomposition temperature $\left(\mathrm{DT}_{\max }\right)$ of $331^{\circ} \mathrm{C}$.
3.2. Characterization of Thermoplastic Starch and Thermoplastic Grafted Starch. While obtaining thermoplastic starch (TPS) and thermoplastic grafted starch (TPGS), the starch and starch grafted granules lost their granular structure due to the presence of plasticizers (water, glycerol, or sorbitol), the heat, and the high shear stress conditions in the mixer. It has been reported in the literature that this happens due to the rupture of the granular starch with a decrease in the hydrogen bonds and melting of the starch due to the decrease of its melt temperature by the presence of the plasticizer $[4,35]$.

Figure 4 shows the effect of the grafted polymer and the plasticizer on the mechanical properties of thermoplastic starch. For TPS, the stress-deformation curves for both plasticizers show that the stress increases continuously with strain without yield until fracture, which is typically referred to as plastic behavior based on the elongation at break. For TPS with sorbitol (Figure 4(b)), the stress increases compared to TPS with glycerol, and the elongation decreases. It has been shown that the macroscopic behavior of the TPS with sorbitol shows considerable variations depending on the amount of sorbitol added, indicating that there are two types of behavior in starch containing materials plasticized by sorbitol. At a low amount of plasticizer $(<27 \%)$, the materials were shown to be brittle, whereas when the amount of sorbitol increased $(>27 \%)$, it fulfilled the function of a plasticizer and the materials had a plastic mechanical behavior [36]. The TPGS has lower mechanical properties compared to TPS. The PCL graft results in materials with lower Young's moduli and stress but with higher elongation. A strain at break greater than $300 \%$ was obtained for TPGS with $43 \%$ of PCL and 25\% of glycerol or sorbitol plasticizers. It is reported that the PCL polymer possesses an important elongation at break and medium modulus [5]. In the TPGS with $26 \%$ of PCL where sorbitol was used as the plasticizer, an increase in Young's modulus, stress, and elongation at break was obtained in 


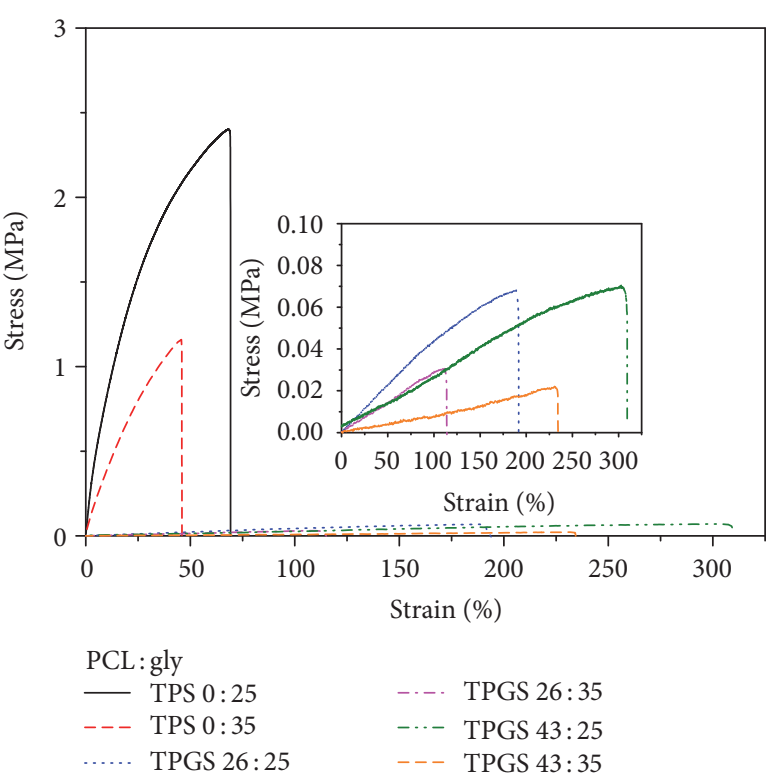

(a)

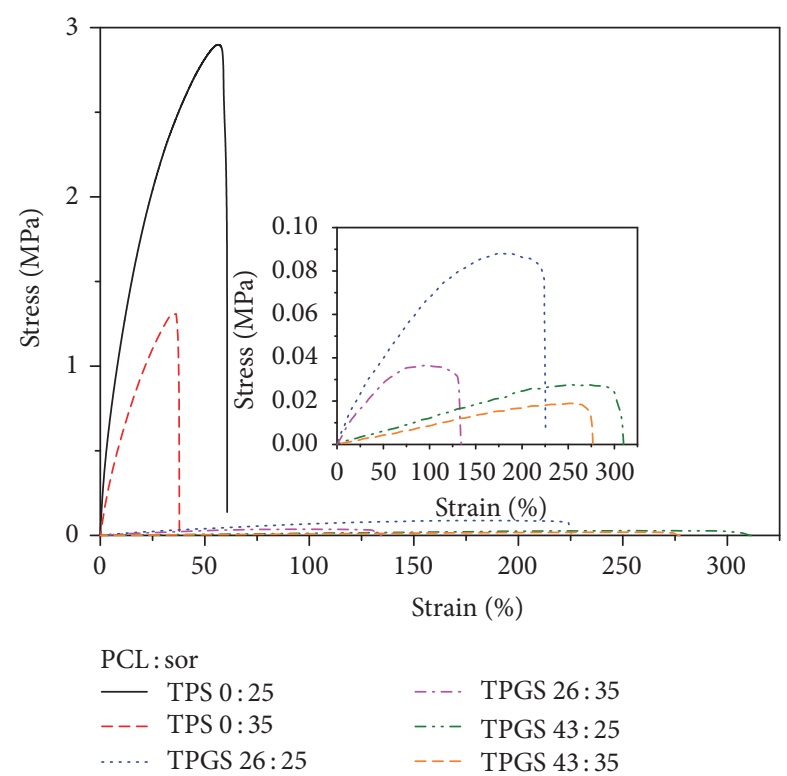

(b)

FIGURE 4: Effect of grafted polymer and plasticizers on the mechanical properties of thermoplastic starch with the formulations of 50/25/25 and 50/15/35: (a) starch or grafted starch/glycerol and (b) starch or grafted starch/sorbitol.

comparison with the materials obtained with glycerol. For both plasticizers, where TPGS was obtained with $43 \%$ of PCL, the mechanical properties were similar.

Figure 5 shows the fracture surface of the specimen after the tensile test. Disintegration of the granules was observed due to the action of plasticizers during high shear mixing. A rough surface was observed for the TPS (Figures 5(a) and 5(b)) and as the amount of grafted polymer was increased a smooth surface with greater homogeneity was obtained (Figures 5(c)-5(f)). Some authors have reported that roughness can refer to materials with semicrystalline behavior $[12,14]$.

Figure 6 shows the effect of the grafted PCL and the plasticizers on the storage modulus and the $\tan \delta$ curves of TPS and TPGS. The TPS with glycerol as the plasticizer showed two reductions in the storage modulus (Figure 6(a)); this occurred in a range from -65 to $-23^{\circ} \mathrm{C}$ and -12 to $12^{\circ} \mathrm{C}$, with two maxima in the $\tan \delta$ curve (Figure 6(b)) at -41 and $14^{\circ} \mathrm{C}$. In the storage modulus curve from TPS with sorbitol as the plasticizer (Figure 6(a)), a decrease between -27 and $18^{\circ} \mathrm{C}$ is observed with maximum at $7^{\circ} \mathrm{C}$ (Figure $6(\mathrm{~b})$ ). Peaks of $\tan \delta$ have been reported to be related to polymer relaxations due to primary (such as glass transition temperature, $\mathrm{Tg}$ ) and secondary transitions [15, 37]. For plasticized starch with glycerol, the position of the transition towards higher temperatures is associated with the $\mathrm{Tg}$ of a phase with high starch content, while the signal towards lower temperatures refers to the Tg of a plasticizer-rich phase $[9,15]$. On the other hand, the single peak for TPS with sorbitol as the plasticizer indicates that a more homogeneous material was obtained [15].

For the TPGS plasticized with glycerol, a lower storage modulus was obtained in comparison with TPS, and very pronounced reductions by one order of magnitude are observed in the modulus curves for TPGS with $43 \%$ of grafted PCL (Figure 6(a)). This decrease can be attributed to the more flexible TPGS material compared to TPS due to the higher plasticization of the ungrafted starch matrix and the low $\mathrm{Tg}\left(-60^{\circ} \mathrm{C}\right)$ of PCL, and it is in accordance with the mechanical properties of these materials. In the $\tan \delta$ curves, a shoulder is observed at $-35^{\circ} \mathrm{C}$ in all the TPGS samples with glycerol (Figure 6(b)). It has been reported that this shoulder corresponds to an overlap of the Tg of PCL and to the secondary relaxation of the plasticized starch [5]. The peak associated with the glass transition of the plasticized starch can be clearly observed and this temperature depends on the PCL content in the starch-g-PCL fraction. At a PCL content of $43 \%$, the transition shows a maximum at $15^{\circ} \mathrm{C}$ (Figure 6(b)).

The TPGS samples plasticized with sorbitol have a higher modulus than the TPGS samples plasticized with glycerol, and only one decrease is observed in the modulus curves (Figure 6(a)). Moreover, one transition is observed for all of these materials. For the smallest addition of PCL the maximum transition values are observed at $38^{\circ} \mathrm{C}$. However, for higher additions of polymer, the maximum value decreased to $-3^{\circ} \mathrm{C}$ (Figure 6(b)). This is consistent with the data presented in the mechanical tests, where a larger amount of PCL in TPGS results in a more plastic behavior.

Figure 7 shows the loss of mass due to thermal degradation of thermoplastic starch and thermoplastic grafted starch, which is obtained by TG analysis. The thermogravimetric curve of TPS with glycerol as the plasticizer (Figure 7(a)) shows the occurrence of a mass loss process below $260^{\circ} \mathrm{C}$, between 260 and $315^{\circ} \mathrm{C}$, and above $315^{\circ} \mathrm{C}$. The first mass loss was attributed to a loss of moisture and plasticizer and the 


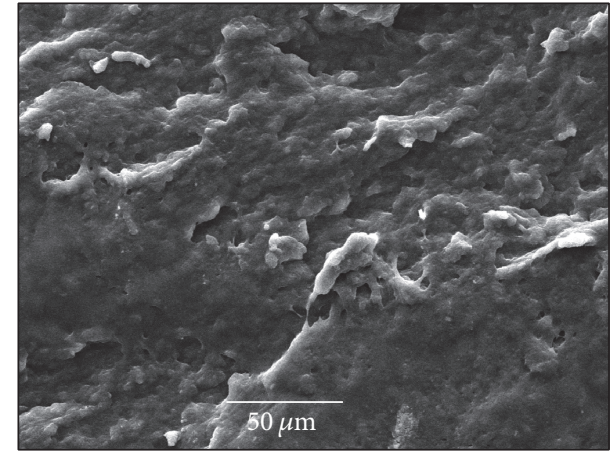

(a)

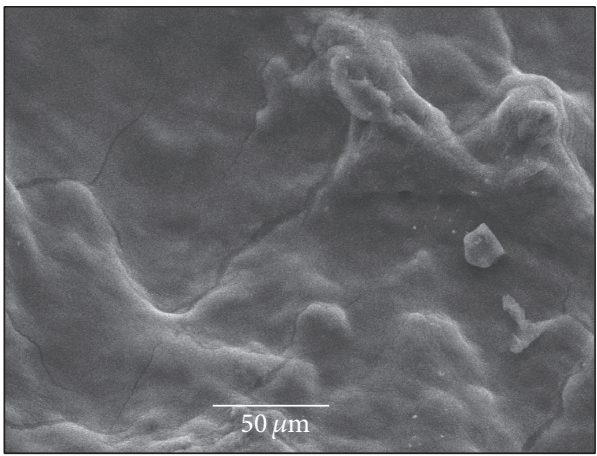

(c)

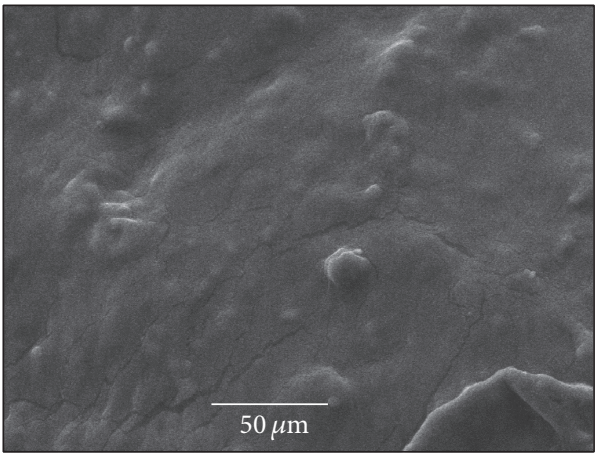

(e)

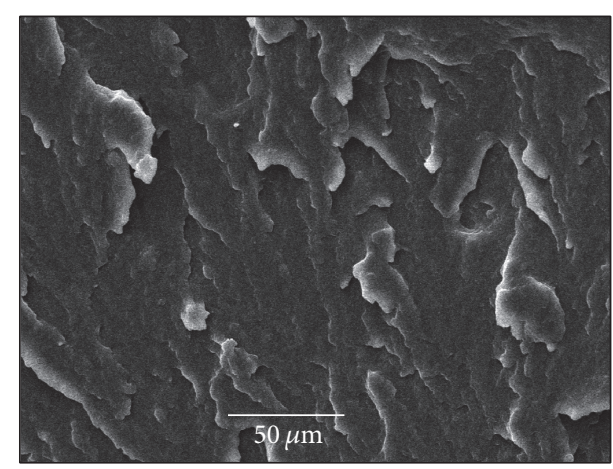

(b)

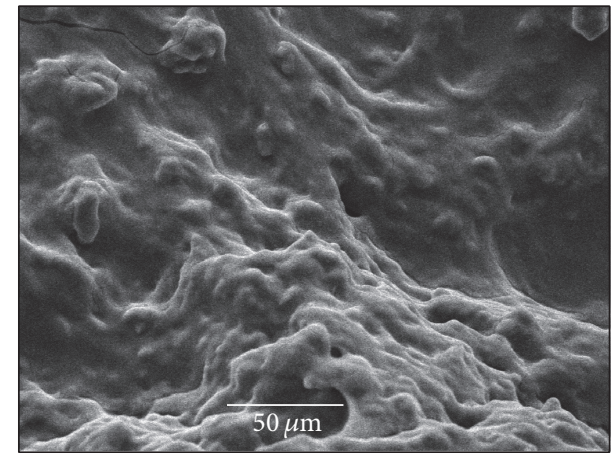

(d)

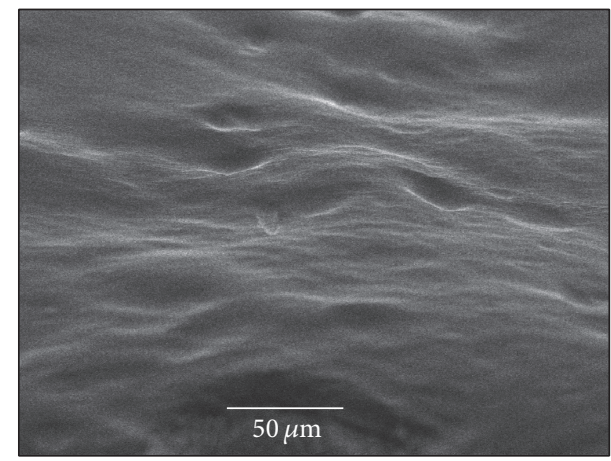

(f)

FIGURE 5: SEM micrographs of rupture zones of TPS with glycerol (a) or sorbitol (b). SEM micrographs of rupture zones of TPGS with 26\% of PCL, with glycerol (c) or sorbitol (d), and TPGS with 43\% of PCL, with glycerol (e) or sorbitol (f).

latter to the degradation of the starch and char formation $[16,20]$. The maximum decomposition temperature $\left(\mathrm{DT}_{\max }\right)$ of TPS with glycerol was observed as two peaks in the DTGA curves (Figure $7(\mathrm{~b})$ ) at 306 and $335^{\circ} \mathrm{C}$ due to the different degradation rates of the polymers composing the starch (amylose and amylopectin) [16]. For TPGS with glycerol as the plasticizer, the second step occurs at a low temperature compared with TPS due to the thermal degradation of the starch-g-PCL; in addition, a large mass loss is observed in the range of $43-338^{\circ} \mathrm{C}(50 \%)$. This behavior is more prominent for the material with a higher amount of PCL ( $43 \%$ addition), and two peaks were observed at 317 and $334^{\circ} \mathrm{C}$. Other authors have observed similar signs [38]. The thermal degradation of the ungrafted starch in the TPGS is observed at the same range temperature of the starch.

The TPS and TPGS with sorbitol as the plasticizer (Figure 7(a)) had a higher thermal stability than the materials plasticized with glycerol, which could be due to a better interaction between the sorbitol and the starch chains. Some authors have attributed this better interaction to the molecular weight of this plasticizer $[12,17]$. In this case, the thermal degradation of the ungrafted and PCL-grafted starch is observed at the same zone, and only the peaks (DT $\left.\mathrm{Dax}_{\max }\right)$ at 335,315 , and $309^{\circ} \mathrm{C}$ are attributed to TPS, TPGS with $26 \%$ of PCL, and TPGS with $43 \%$ of PCL, respectively. The lower $\mathrm{DT}_{\max }$ for TPGS compared to TPS could occur because the 


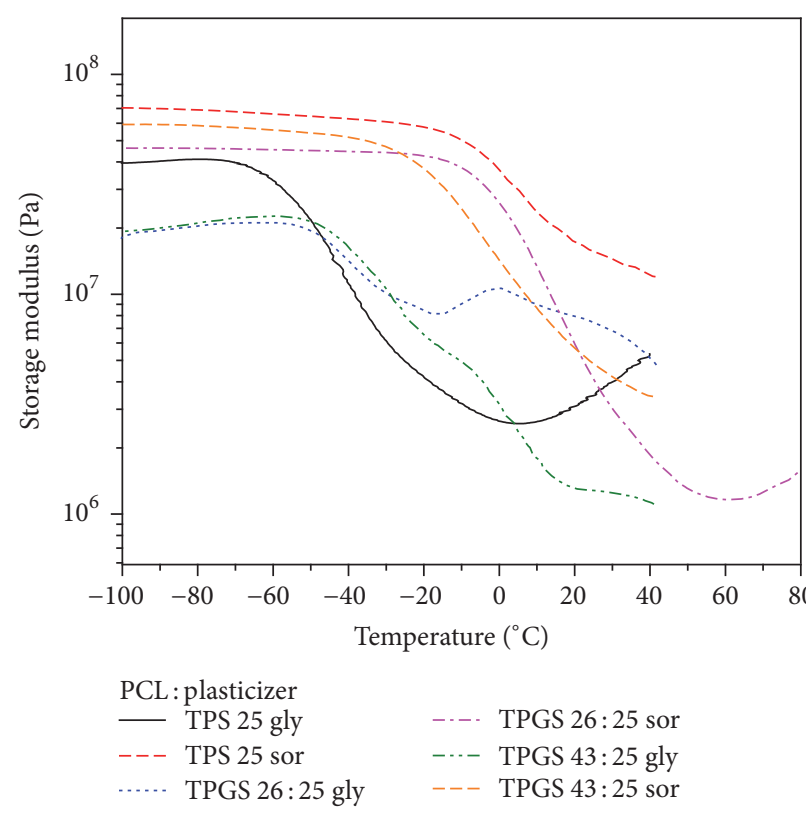

(a)

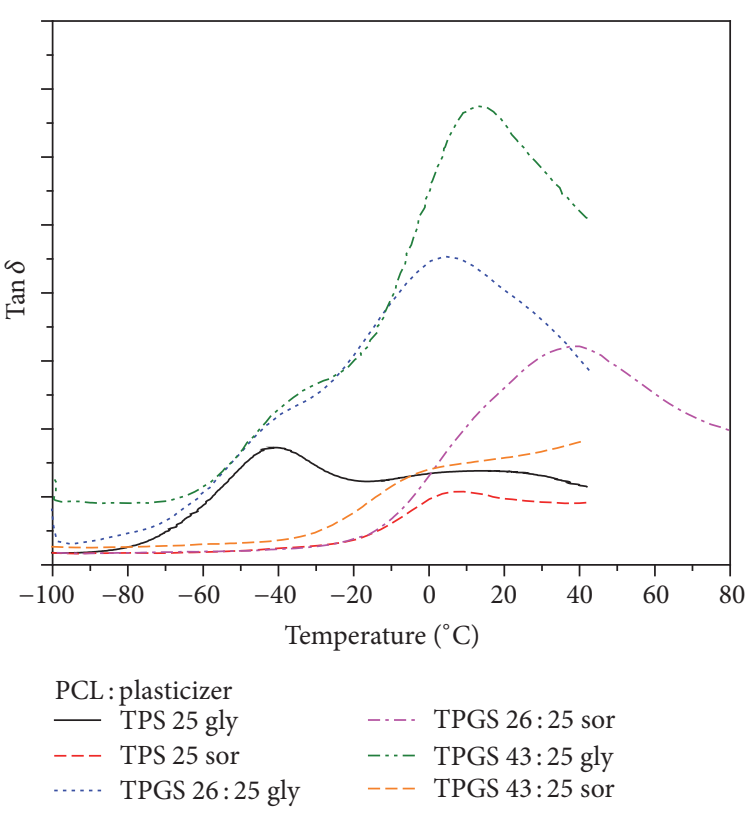

(b)

FIGURE 6: Storage modulus (a) and Tan $\delta$ (b) curves of TPS and TPGS with glycerol or sorbitol as the plasticizer.

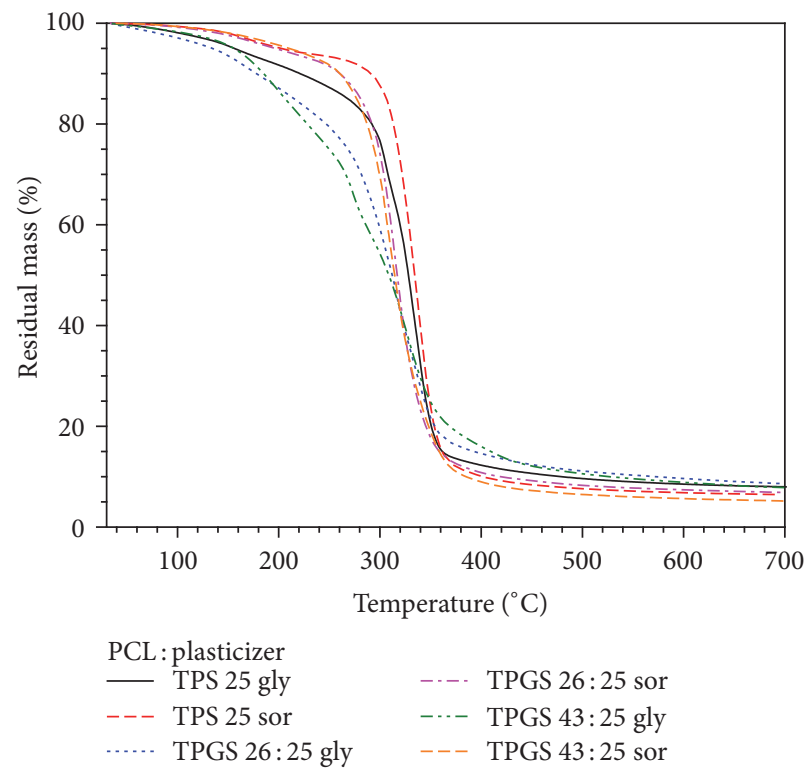

(a)

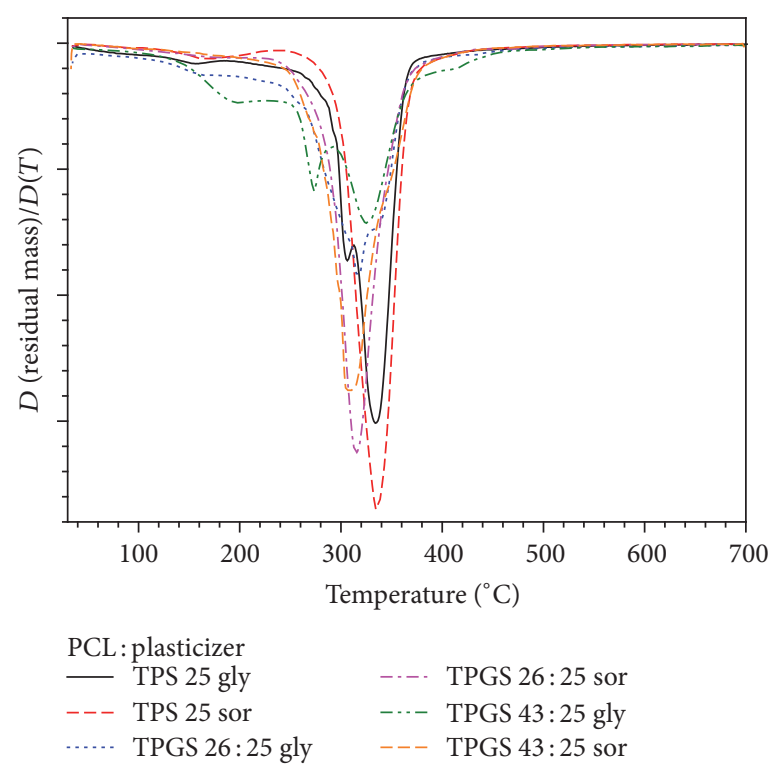

(b)

FIGURE 7: TGA (a) and DTGA (b) curves of TPS and TPGS with glycerol or sorbitol. The ratio of starch or grafted starch/water/glycerol or sorbitol of 50/25/25 was used.

degradation products of caprolactone increase the rate of degradation of starch.

Figure 8 shows the X-ray diffractograms of the TPS and TPGS plasticized with glycerol or sorbitol. In the TPS with glycerol (Figure $8(a)$ ), the crystallinity of starch was modified and the B-type and V-type crystallinities are formed [39, 40]. The B-type crystallinity in starch materials that contain glycerol as plasticizer is represented by the crystals forming some outer chains of the branched polymer of the starch (amylopectin) of smaller size with a maximum at $16.96^{\circ}$ [39, 41-44]. The V-type crystallinity is related to the process of recrystallization of the linear polymer of the starch (amylose) due to the type of processing to obtain the thermoplastic starch and is represented with the maxima at $12.96-19.76^{\circ}$ $[39,41,43]$. The TPGS with PCL and glycerol (Figure 8(a)) exhibits two different patterns. The first pattern is for the 


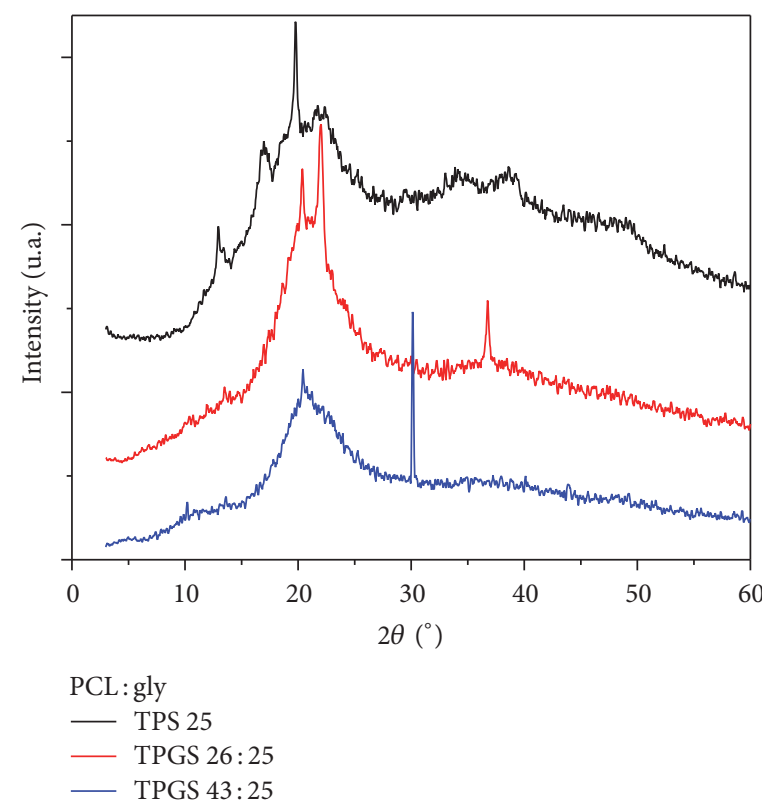

(a)

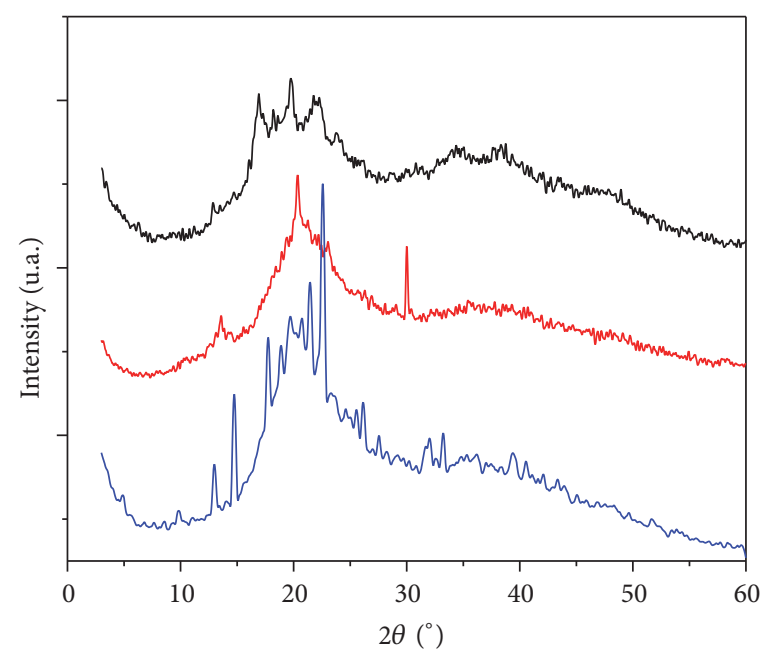

PCL: sor
- TPS 25
- TPGS $26: 25$
- TPGS $43: 25$

FIGURE 8: X-ray diffractograms of TPS and TPGS with (a) glycerol and (b) sorbitol. The ratio of starch or grafted starch/water/plasticizer of $50 / 25 / 25$ was used.

$26 \%$ of grafted PCL, where two intense peaks are observed at 20.4 and $22.04^{\circ}$. The second pattern is presented for the other TPGS sample with $43 \%$ of the grafted polymer, which exhibits only a broad peak at $20.44^{\circ}$. These maximums are related to the V-type crystallinity of TPS. A change was also observed in the diffractograms in the height of the peak referring to the PCL; when the amount of PCL was greater, the height decreased indicating a lower crystallinity in the materials.

TPS and TPGS with sorbitol as the plasticizer (Figure 8(b)) show a similar behavior compared to TPS with glycerol as the plasticizer. In the TPS with sorbitol, similar peaks to those observed in the TPS with glycerol as the plasticizer are obtained. For TPGS with the least amount of grafted polymers (26\% of PCL), only three signals appear: a peak at $13.6^{\circ}$, a broad peak at $20.4^{\circ}$, and a peak at $30^{\circ}$, which indicates good dispersion of the plasticizer in the mixture due to the presence of the grafted polymer. The broad peak is an indication of the change in crystal from A-type to V-type [39]. When the amount of grafted polymer increased (43\% PCL), strong signals were observed, which likely indicates a retrogradation of the material and an overlapping between the peaks from the grafted polymer and the plasticizer.

Figure 9 shows the percentage of weight loss of the TPS and TPGS after enzymatic degradation by 48 hours. It can be seen that the percentage of weight loss is above $95 \%$ for all materials evaluated. TPGS with $43 \%$ of grafted PCL had lower weight loss percentages (95-96\%) compared to the lesser amount of grafted polymer (97-98\%) and nongrafted thermoplastic starches (98-99\%), which is in agreement with the different rates of enzymatic degradation of starch and PCL with the enzymes used in this work. The starch-forming polymers, amylose and amylopectin, are readily hydrolysed

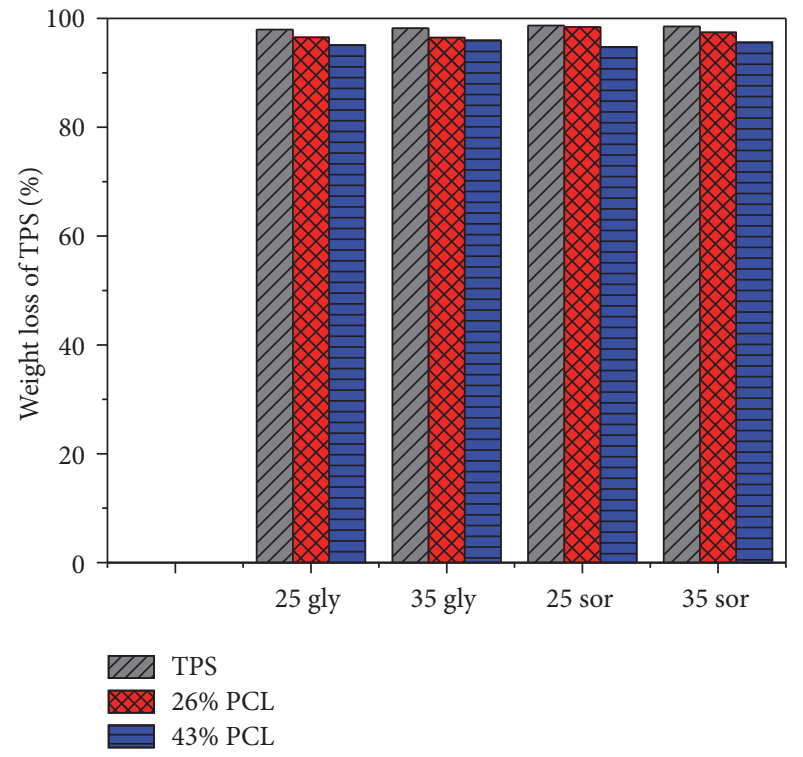

FIGURE 9: Weight loss of TPS and TPGS after enzymatic degradation.

by enzymes [45]. The amylase initiates the breakdown of the amylose glucoside linkage 1-4 [22, 45-47], while the glucoamylase attacks the 1-6 linkages of amylopectin, reducing the size of the starch chains. These smaller chains are solubilized in the aqueous phase and this is recorded as a weight loss $[22,45]$. On the other hand, these enzymes also attack the $\mathrm{C}-\mathrm{O}$ bonds of the ester groups of the PCL which results in the rupture of the polymer chains. The remaining solid residue, after enzymatic degradation, corresponds to 


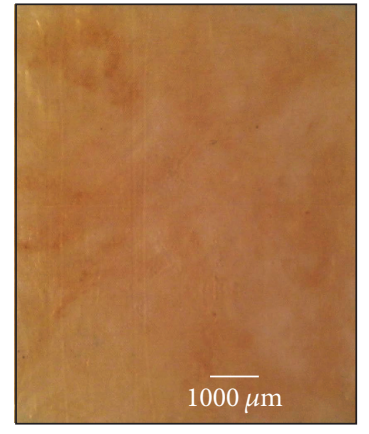

(a)

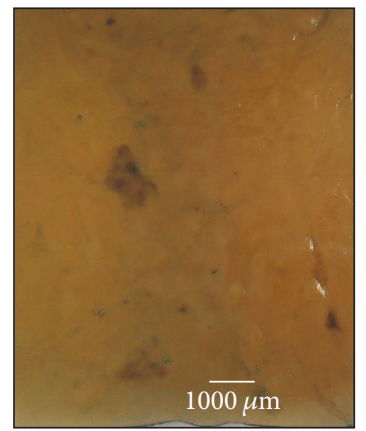

(c)

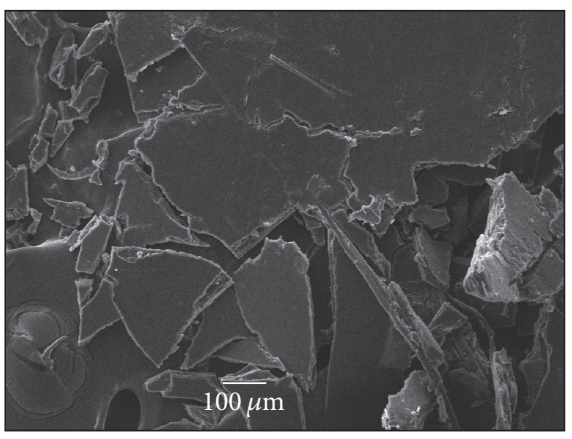

(b)

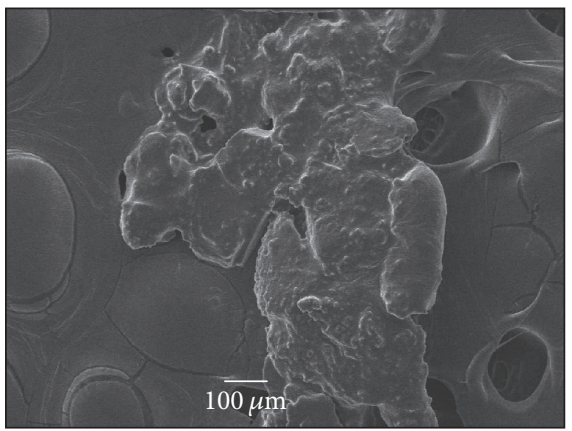

(d)

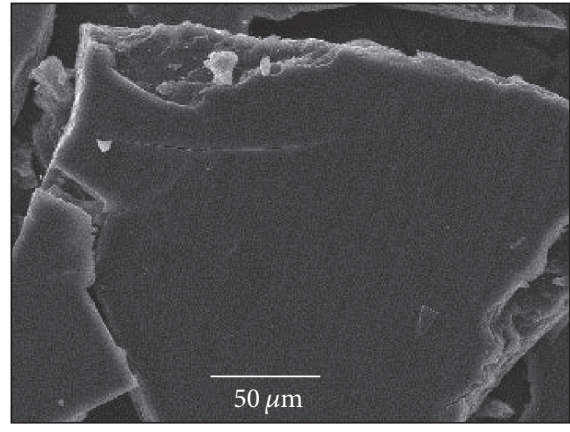

$\left(b^{\prime}\right)$

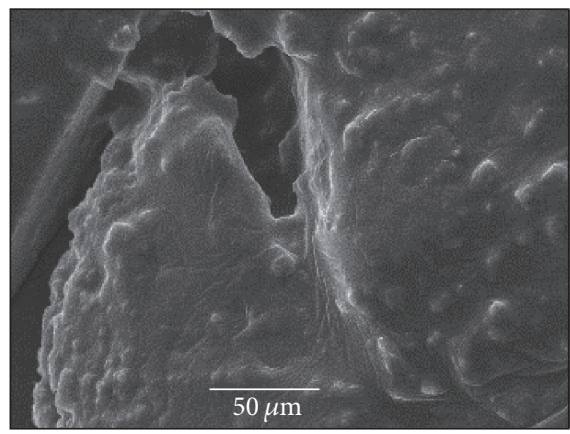

$\left(d^{\prime}\right)$

FIGURE 10: Images of TPGS films before enzymatic degradation: (a) 26 PCL 25 gly and (c) 43 PCL 25 gly; SEM micrographs of residues obtained after enzymatic degradation: (b) 26 PCL 25 gly and (d) 43 PCL 25 gly.

PCL chains with hydroxyl or acid group as chain ends. There are no notable changes in the weight loss due to the type of plasticizer used.

Figure 10 shows SEM micrographs of the residues obtained after TPGS biodegradation. After biodegradation the TPGS films were disintegrated and the micrographs of the residues of TPGS with the least PCL (26\%, Figures 10(b) and $10\left(b^{\prime}\right)$ ) show a surface eroded from the inside to the surface; this behavior suggests the formation of a starch-gpolycaprolactone layer on the surface of the materials. When the PCL is present in the largest amount in the TPGS (43\%, Figures $10(d)$ and $10\left(d^{\prime}\right)$ ) a rough surface is observed due to the minor plasticization for the starch-g-PCL with high content of PCL. When high starch contents are present, greater accessibility to the phase formed by this material is obtained, which is reflected with higher percentages of degradation [45].

Figure 11 displays infrared spectra of the residues of TPGS after enzymatic degradation. All the biodegraded materials show a decrease in the broad band corresponding to the hydroxyl groups $(-\mathrm{OH})$ of starch; this could be due to the solubilization in the aqueous medium of the degraded starch chains as well as the plasticizer. In addition, the band at $1160 \mathrm{~cm}^{-1}$ corresponding to the glucosidic bonds $-\mathrm{C}-\mathrm{O}-\mathrm{C}-$ [46] shows a decrease in the intensity, confirming starch degradation. The intense peak at $1736 \mathrm{~cm}^{-1}$ that corresponds to the stretching of the carbonyl group $(\mathrm{C}=\mathrm{O})$ present in the PCL confirms the presence of the grafted polymer in the

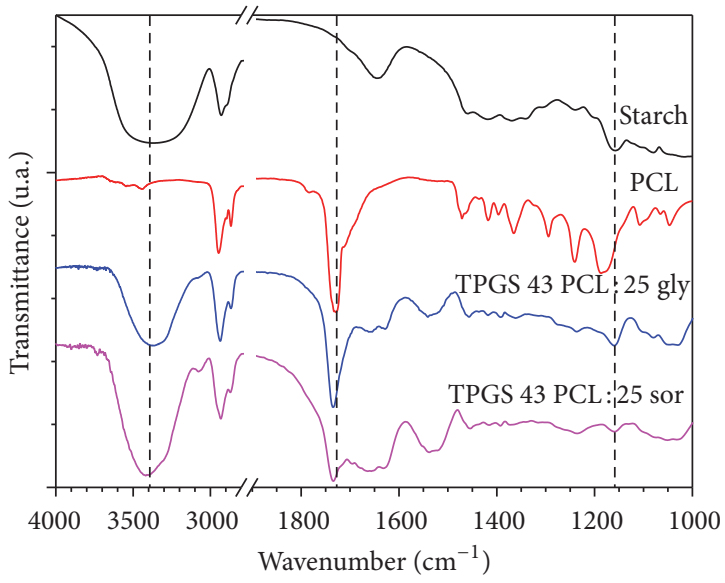

FIGURE 11: FTIR spectra of starch and PCL and the residues after the TPGS enzymatic biodegradation.

residues obtained after the enzymatic hydrolysis. This is more notorious for the TPGS obtained using glycerol as plasticizer.

Figure 12 shows the thermal degradation of the TPGS and the residues obtained after enzymatic hydrolysis. The presence of three mass loss processes for the TPGS can be observed, which are best defined in the DTGA curves. For the residues of TPGS grafted with PCL (Figures 12(a) and 12(b)) after enzymatic hydrolysis two mass loss processes are 


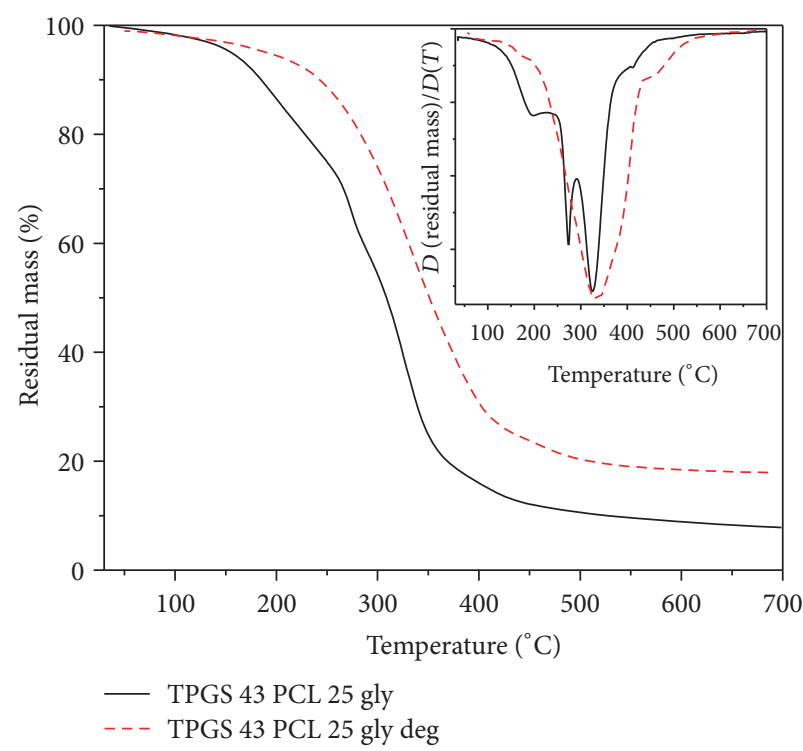

(a)

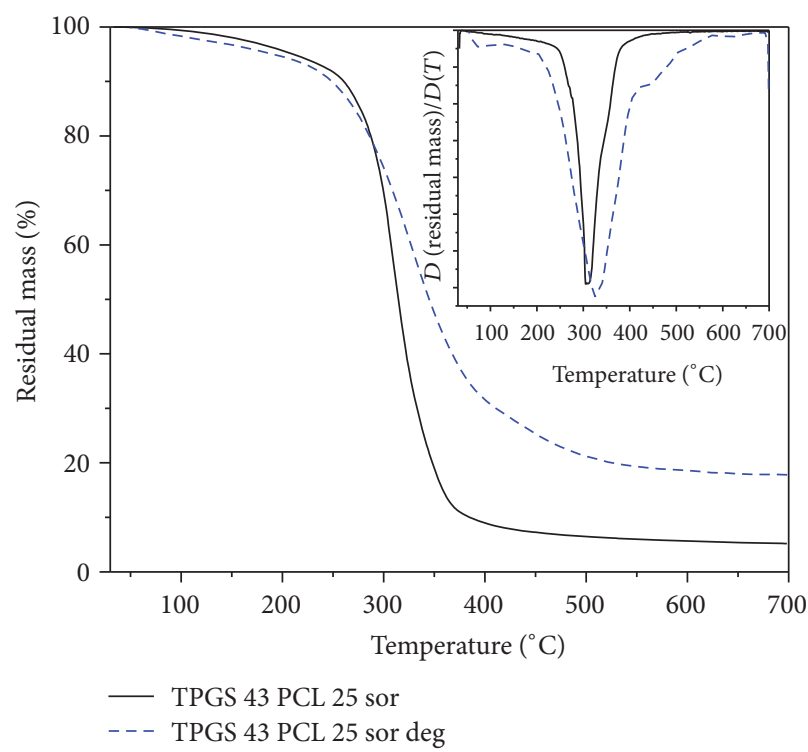

(b)

FIGURE 12: TGA and DTGA curves of TPGS before degradation and residues obtained after enzymatic hydrolysis: (a) TPGS 43 PCL 25 gly and (b) TPGS 43 PCL 25 sor.

observed and the main maximum decomposition temperature $\left(\mathrm{DT}_{\max }\right)$ shows a shift towards higher temperatures, attributed to the polymer grafted (PCL) confirming the biodegradation of the starch chains. The similar decomposition in the range between 50 and $300^{\circ} \mathrm{C}$ of the TPGS obtained using sorbitol and the residues obtained after its enzymatic degradation indicates the presence of starch or plasticizer in these residues due to the lower degradation of the starch-gPCL at high PCL content.

\section{Conclusions}

Granular starch with grafted PCL was obtained, and the polymer grafting was verified by different physicochemical techniques. Modifying the concentration of catalyst or the starch/monomer ratio resulted in different levels of the grafted polymer. The grafted chains produced changes in the surface of these particles and resulted in more hydrophobic materials.

Thermoplastic grafted starches (TPGS) were obtained with glycerol and sorbitol as the plasticizers. The mechanical properties of thermoplastic starch can be modified by the use of grafted polymers. The use of rubbery polymers (PCL) increases the flexibility of thermoplastic grafted starch (TPGS) compared to thermoplastic starch (TPS), and it enables the preparation of a wide range of materials by modifying the ratio of $\operatorname{starch} / \mathcal{E}$-caprolactone in the grafted polymer. Enzymatic hydrolysis of starch in TPS and TPGS using amylolytic enzymes shows that thermoplastics were almost completely biodegraded. The residues obtained from the PCL-grafted TPGS after enzymatic degradation are mainly PCL chains indicating the higher rate of starch degradation.

\section{Conflicts of Interest}

The authors declare that they have no conflicts of interest regarding the publication of this paper.

\section{Acknowledgments}

The authors wish to thank the National Council of Science and Technology in Mexico (CONACyT) for financial support of the Ph.D. thesis of Z. B. Cuevas-Carballo. The X-ray diffraction analysis was performed at the National Laboratory of Nano and Biomaterials (financed by Fomix-Yucatán and CONACyT), CINVESTAV-IPN, Mérida Unit. The authors also thank Dr. Patricia Quintana for access to LANNBIO and M. C. Daniel Aguilar for technical support in obtaining the diffractograms.

\section{References}

[1] A. C. Correa, V. B. Carmona, J. A. Simão, L. H. Capparelli Mattoso, and J. M. Marconcini, "Biodegradable blends of urea plasticized thermoplastic starch (UTPS) and poly $(\varepsilon$ caprolactone) (PCL): Morphological, rheological, thermal and mechanical properties," Carbohydrate Polymers, vol. 167, pp. 177-184, 2017.

[2] A. Zerroukhi, T. Jeanmaire, C. Raveyre, and A. Ainser, "Synthesis and characterization of hydrophobically modified starch by ring opening polymerization using imidazole as catalyst," Starch/Staerke, vol. 64, no. 8, pp. 613-620, 2012.

[3] L. Chen, Y. Ni, X. Bian et al., "A novel approach to grafting polymerization of $\varepsilon$-caprolactone onto starch granules," Carbohydrate Polymers, vol. 60, no. 1, pp. 103-109, 2005. 
[4] B. Ghanbarzadeh and H. Almasi, BiodegradationLife of Science, InTech, Rijekaw Croatia, 2013.

[5] L. Averous, L. Moro, P. Dole, and C. Fringant, "Properties of thermoplastic blends: starch-polycaprolactone," Polymer, vol. 41, no. 11, pp. 4157-4167, 2000.

[6] F. J. Aranda-García, R. González-Núñez, C. F. Jasso-Gastinel, and E. Mendizábal, "Water absorption and thermomechanical characterization of extruded starch/poly(lactic acid)/agave bagasse fiber bioplastic composites," International Journal of Polymer Science, vol. 2015, Article ID 343294, 7 pages, 2015.

[7] G. A. Arboleda, C. E. Montilla, H. S. Villada, and G. A. Varona, "Obtaining a flexible film elaborated from cassava thermoplastic starch and polylactic acid," International Journal of Polymer Science, vol. 2015, Article ID 627268, 9 pages, 2015.

[8] M.-C. Li, J. K. Lee, and U. R. Cho, "Synthesis, characterization, and enzymatic degradation of starch-grafted poly(methyl methacrylate) copolymer films," Journal of Applied Polymer Science, vol. 125, no. 1, pp. 405-414, 2012.

[9] P. M. Forssell, J. M. Mikkilä, G. K. Moates, and R. Parker, "Phase and glass transition behaviour of concentrated barley starchglycerol-water mixtures, a model for thermoplastic starch," Carbohydrate Polymers, vol. 34, no. 4, pp. 275-282, 1998.

[10] Q. Shi, C. Chen, L. Gao, L. Jiao, H. Xu, and W. Guo, "Physical and degradation properties of binary or ternary blends composed of poly (lactic acid), thermoplastic starch and GMA grafted POE," Polymer Degradation and Stability, vol. 96, no. 1, pp. 175-182, 2011.

[11] M. Vikman, S. H. D. Hulleman, M. Van Der Zee, P. Myllärinen, and H. Feil, "Morphology and enzymatic degradation of thermoplastic starch-polycaprolactone blends," Journal of Applied Polymer Science, vol. 74, no. 11, pp. 2594-2604, 1999.

[12] J. Castaño, R. Bouza, S. Rodríguez-Llamazares, C. Carrasco, and R. V. B. Vinicius, "Processing and characterization of starchbased materials from pehuen seeds (Araucaria araucana (Mol) K. Koch)," Carbohydrate Polymers, vol. 88, no. 1, pp. 299-307, 2012.

[13] L. Chen, X. Qiu, M. Deng et al., "The starch grafted poly(llactide) and the physical properties of its blending composites," Polymer, vol. 46, no. 15, pp. 5723-5729, 2005.

[14] X. Y. Zhou, Y. F. Cui, D. M. Jia, and D. Xie, "Effect of a complex plasticizer on the structure and properties of the thermoplastic PVA/starch blends," Polymer - Plastics Technology and Engineering, vol. 48, no. 5, pp. 489-495, 2009.

[15] H. Schmitt, A. Guidez, K. Prashantha, J. Soulestin, M. F. Lacrampe, and P. Krawczak, "Studies on the effect of storage time and plasticizers on the structural variations in thermoplastic starch," Carbohydrate Polymers, vol. 115, pp. 364-372, 2015.

[16] J. F. Mano, D. Koniarova, and R. L. Reis, “Thermal properties of thermoplastic starch/synthetic polymer blends with potential biomedical applicability," Journal of Materials Science: Materials in Medicine, vol. 14, no. 2, pp. 127-135, 2003.

[17] X. Qiao, Z. Tang, and K. Sun, "Plasticization of corn starch by polyol mixtures," Carbohydrate Polymers, vol. 83, no. 2, pp. 659664, 2011.

[18] J. Ren, H. Fu, T. Ren, and W. Yuan, "Preparation, characterization and properties of binary and ternary blends with thermoplastic starch, poly(lactic acid) and poly(butylene adipate-coterephthalate)," Carbohydrate Polymers, vol. 77, no. 3, pp. 576$582,2009$.

[19] K. Kaewtatip, V. Tanrattanakul, K. M. Szécsényi, J. Pavličević, and J. Budinski-Simendić, "Thermal properties and morphology of cassava starch grafted with different content of polystyrene," Journal of Thermal Analysis and Calorimetry, vol. 102, no. 3, pp. 1035-1041, 2010.

[20] G. Canché-Escamilla, M. Canché-Canché, S. Duarte-Aranda, M. Cáceres-Farfán, and R. Borges-Argáez, "Mechanical properties and biodegradation of thermoplastic starches obtained from grafted starches with acrylics," Carbohydrate Polymers, vol. 86, no. 4, pp. 1501-1508, 2011.

[21] D. Rutot, P. Degée, R. Narayan, and P. Dubois, "Aliphatic polyester-grafted starch composites by in situ ring opening polymerization," Composite Interfaces, vol. 7, no. 3, pp. 215-225, 2000.

[22] C. S. Tena-Salcido, F. J. Rodríguez-González, M. L. MéndezHernández, and J. C. Contreras-Esquivel, "Effect of morphology on the biodegradation of thermoplastic starch in LDPE/TPS blends," Polymer Bulletin, vol. 60, no. 5, pp. 677-688, 2008.

[23] L. Najemi, T. Jeanmaire, A. Zerroukhi, and M. Raihane, "Organic catalyst for ring opening polymerization of $\varepsilon$-caprolactone in bulk. Route to starch-graft-polycaprolactone," Starch/ Staerke, vol. 62, no. 3-4, pp. 147-154, 2010.

[24] M. Vera-Pacheco, H. Vázquez-Torres, and G. CanchéEscamilla, "Preparation and characterization of hydrogels obtained by grafting of acrylonitrile onto cassava starch by ceric ion initiation," Journal of Applied Polymer Science, vol. 47, no. 1, pp. 53-59, 1993.

[25] ASTM, in Proceedings of the D638-14. Standard test method for tensile properties of plastics, ASTM International, West Conshohocken, PA, USA, 2014.

[26] ASTM, in Proceedings of the D618-13. Standard practice for conditioning plastics for testing, ASTM International, West Conshohocken, PA, USA, 2013.

[27] M. V. Moreno-Chulim, F. Barahona-Perez, and G. CancheEscamilla, "Biodegradation of starch and acrylic-grafted starch by Aspergillus niger," Journal of Applied Polymer Science, vol. 89, no. 10, pp. 2764-2770, 2003.

[28] N. B. Colthup, L. H. Daly, and S. E. Wiberley, Introduction to Infrared And Raman Spectroscopy, Elsevier, Cambridge, MA, USA, 3rd edition, 1990.

[29] W. L. Walton and R. B. Hughes, "Infrared identification of fumarates and maleates," Analytical Chemistry, vol. 28, no. 9, pp. 1388-1391, 1956.

[30] A. R. Katritzky, J. M. Lagowski, and J. A. T. Beard, "The infra-red spectra of esters-I Methyl, ethyl, n- and i-propyl, and n-, i- and s-butyl esters," Spectrochimica Acta, vol. 16, no. 8, pp. 954-963, 1960.

[31] J. L. Mateos, R. Cetina, E. Olivera, and S. Meza, "The intensity of the carbonyl band in the infrared spectra of methyl benzoates," Journal of Organic Chemistry, vol. 26, no. 7, pp. 2494-2498, 1961.

[32] X. Xie, Q. Liu, and S. W. Cui, "Studies on the granular structure of resistant starches (type 4) from normal, high amylose and waxy corn starch citrates," Food Research International, vol. 39, no. 3, pp. 332-341, 2006.

[33] M. G. Casarrubias-Castillo, G. Méndez-Montealvo, S. L. Rodríguez-Ambriz, M. M. Sánchez-Rivera, and L. A. BelloPérez, "Structural and rheological differences between fruit and cereal starches," Agrociencia, vol. 46, no. 5, pp. 455-466, 2012.

[34] S. Agarwal and C. Speyerer, "Degradable blends of semicrystalline and amorphous branched poly(caprolactone): effect of microstructure on blend properties," Polymer, vol. 51, no. 5, pp. 1024-1032, 2010.

[35] J. Fang and P. Fowler, "The use of starch and its derivatives as biopolymer sources of packaging materials," Journal of Food Agriculture and Environment, vol. 1, pp. 82-84, 2003. 
[36] S. Gaudin, D. Lourdin, D. Le Botlan, J. L. Ilari, and P. Colonna, "Plasticisation and mobility in starch-sorbitol films," Journal of Cereal Science, vol. 29, no. 3, pp. 273-284, 1999.

[37] B. Wunderlich, Thermal Analysis of Polymeric Materials, Springer Science Business Media, Berlin, Germany, 2005.

[38] O. Persenaire, M. Alexandre, P. Degée, and P. Dubois, "Mechanisms and kinetics of thermal degradation of poly $(\varepsilon-$ caprolactone)," Biomacromolecules, vol. 2, no. 1, pp. 288-294, 2001.

[39] J. J. G. Van Soest and P. Essers, "Influence of amyloseamylopectin ratio on properties of extruded starch plastic sheets," Journal of Macromolecular Science - Pure and Applied Chemistry, vol. 34, no. 9, pp. 1665-1689, 1997.

[40] J. J. G. Van Soest, S. H. D. Hulleman, D. De Wit, and J. F. G. Vliegenthart, "Crystallinity in starch bioplastics," Industrial Crops and Products, vol. 5, no. 1, pp. 11-22, 1996.

[41] J. J. G. Van Soest, K. Benes, D. De Wit, and J. F. G. Vliegenthart, "The influence of starch molecular mass on the properties of extruded thermoplastic starch," Polymer, vol. 37, no. 16, pp. 3543-3552, 1996.

[42] J. J. G. Van Soest, D. De Wit, and J. F. G. Vliegenthart, "Mechanical properties of thermoplastic waxy maize starch," Journal of Applied Polymer Science, vol. 61, no. 11, pp. 1927-1937, 1996.

[43] J. J. G. Van Soest, Starch Plastics: Structure-Property Relationships, Universiteit Utrecht, Netherlands.

[44] S. H. D. Hulleman, F. H. P. Janssen, and H. Feil, "The role of water during plasticization of native starches," Polymer, vol. 39, no. 10, pp. 2043-2048, 1998.

[45] M. A. Araújo, A. M. Cunha, and M. Mota, "Enzymatic degradation of starch-based thermoplastic compounds used in protheses: identification of the degradation products in solution," Biomaterials, vol. 25, no. 13, pp. 2687-2693, 2004.

[46] H. S. Azevedo and R. L. Reis, Understanding the enzymatic degradation of biodegradable polymers and strategies to control their degradation rate. Biodegradable systems in tissue engineering and regenerative medicine, CRC Press 177201, Boca Raton, Fla, USA, 2005.

[47] Y. Dumoulin, L. H. Cartilier, and M. A. Mateescu, "Crosslinked amylose tablets containing $\alpha$-amylase: an enzymaticallycontrolled drug release system," Journal of Controlled Release, vol. 60, no. 2-3, pp. 161-167, 1999. 

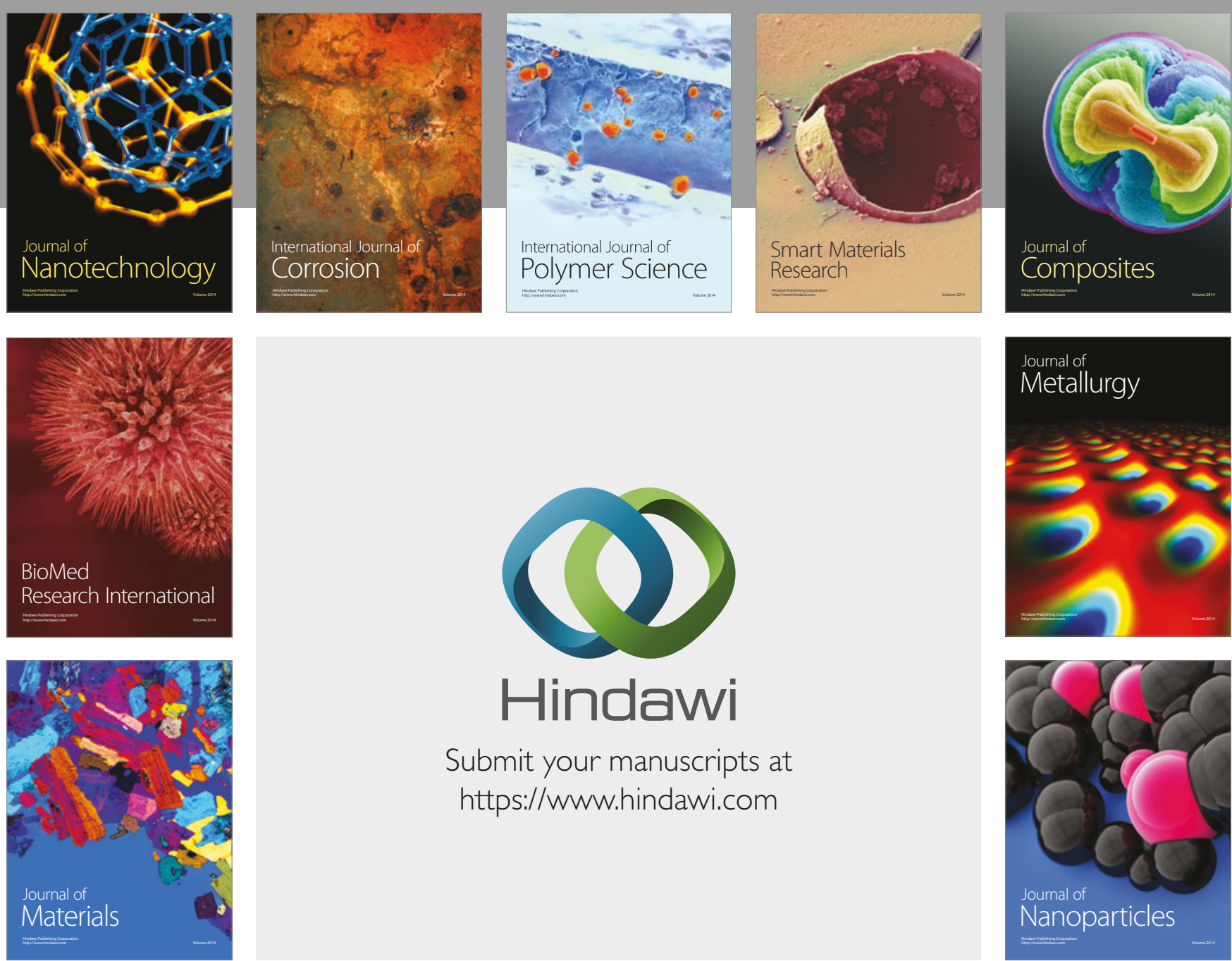

\section{Hindawi}

Submit your manuscripts at

https://www.hindawi.com
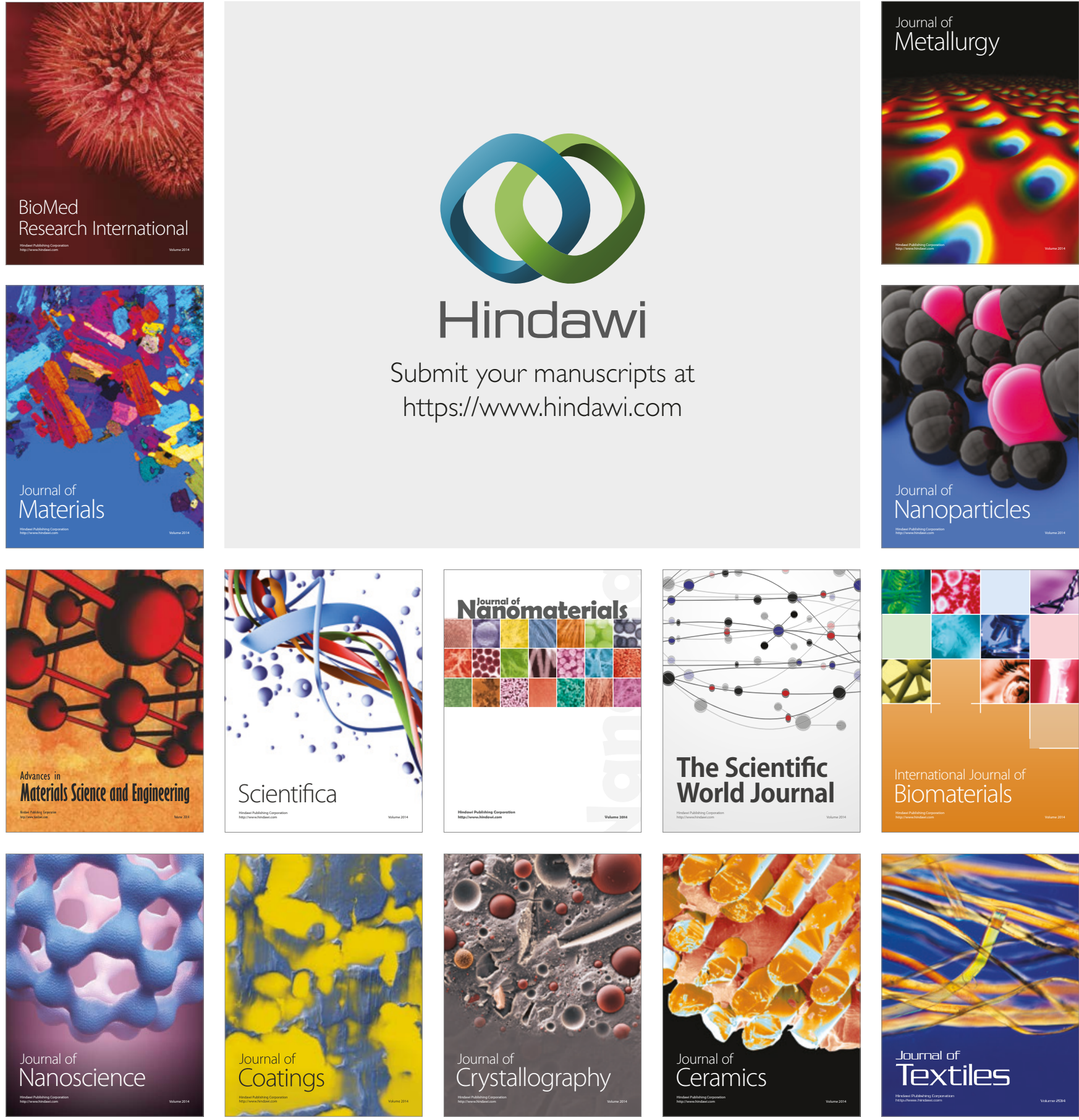

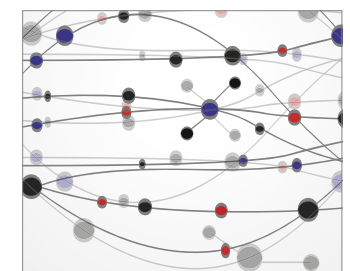

The Scientific World Journal
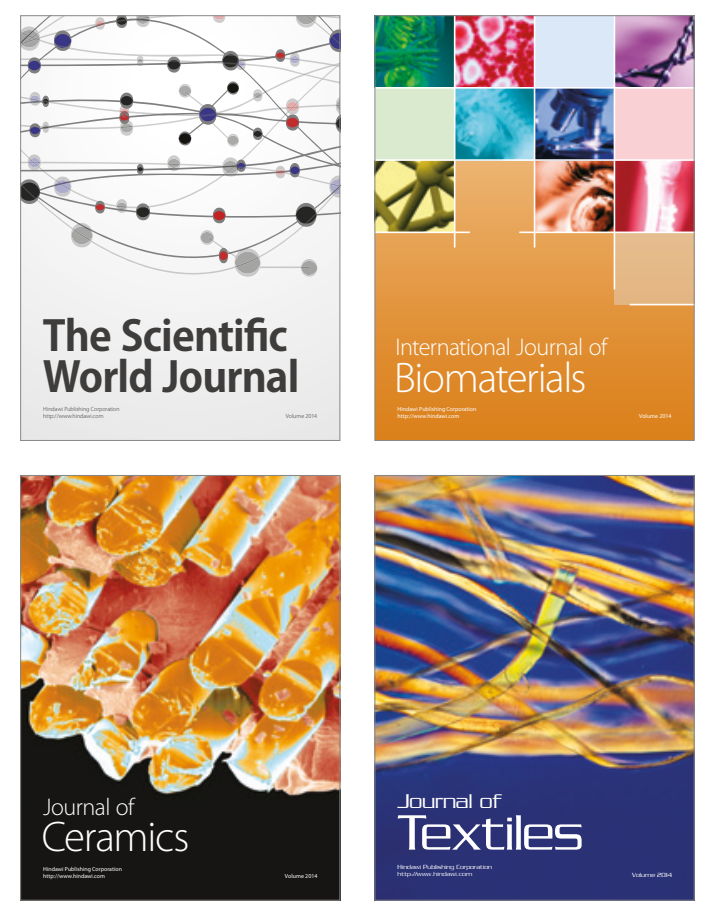